\title{
Effects of esmolol, lidocaine and fentanyl on P wave dispersion, QT, QTc intervals and hemodynamic responses to endotracheal intubation during propofol induction: a comparative study
}

\author{
Volkan Hanci* 1, Serhan Yurtlu ${ }^{2}$, Turgut Karabağ ${ }^{3}$, Dilek Okyay ${ }^{2}$, Sedat Hakimoğlu ${ }^{4}$, \\ Gülay Kayhan ${ }^{5}$, Çağatay Büyüukuysal ${ }^{6}$, Hilal Ayoğlu ${ }^{7}$, Ișı Özkoçak Turan ${ }^{8}$
}

1. MD, Associate Professor, Department of Anesthesiology and Reanimation, School of Medicine, Eylul University, Izmir, Turkey (Formerly Zonguldak Karaelmas University, Zonguldak, Turkey)

2. MD, Assistant Professor, Department of Anesthesiology and Reanimation, School of Medicine, Eylul University, Izmir, Turkey

3. MD, Assistant Professor, Department of Cardiology, School of Medicine, Zonguldak Karaelmas University, Zonguldak, Turkey

4. MD, Assistant Professor, Department of Anesthesiology and Reanimation, Mustafa Kemal University, Hatay, Turkey (Formerly Zonguldak Karaelmas University, Zonguldak, Turkey)

5. MD, Assistant Professor, Department of Anesthesiology and Reanimation, School of Medicine, Inönü University, Malatya, Turkey (Formerly Zonguldak Karaelmas University, Zonguldak, Turkey)

6. MD, Physician, Department of Biostatistics, School of Medicine, Zonguldak Karaelmas University, Zonguldak, Turkey 7. MD, Associate Professor, Department of Anesthesiology and Reanimation, School of Medicine, Zonguldak Karaelmas University, Zonguldak, Turkey

8. MD, Professor, Department of Anesthesiology and Reanimation, School of Medicine, Zonguldak Karaelmas University, Zonguldak, Turkey

Received from the Çanakkale Onsekiz Mart University, School of Medicine, Department of Anesthesiology and Reanimation, Kepez, Çanakkale, Turkey.

Submitted on December 23, 2011. Approved on January 3, 2012.

Keywords:

Electrocardiography;

Intubation, Intratracheal;

Anesthesia;

Propanolamines/

esmolol;

Lidocaine;

Fentanyl;

Propofol.

\begin{abstract}
Background and objectives: In our study we aimed to investigate the effect of esmolol, lidocaine and fentanyl on P-wave dispersion (Pwd), QT and corrected QT (QTC) durations and hemodynamic responses to endotracheal intubation during propofol induction.

Methods: A total of eighty adult patients, American Society of Anesthesiologists (ASA) Physical Status I or II aged 18 to 60 years were included in this prospective, randomised, double-blind study. All patients had control electrocardiograms (ECGs) done before anesthesia induction. The patients were randomised into four equal groups. The control group (Group C) received saline $5 \mathrm{~mL}$, the esmolol group (Group E) received esmolol $0.5 \mathrm{mg} \cdot \mathrm{kg}^{-1}$, the fentanyl group (Group F) received fentanyl $2 \mu \mathrm{g} . \mathrm{kg}^{-1}$ and the lidocaine group (Group L) received lidocaine $1.5 \mathrm{mg} . \mathrm{kg}^{-1}$ before
\end{abstract}

*Corresponding author: Eylul University, School of Medicine, Department of Anesthesiology and Reanimation, Balcova, Izmir, Turkey. E-mail: vhanci@gmail.com; volkanhanci@yahoo.com

ISSN/\$ - see front metter c 2013 Sociedade Brasileira de Anestesiologia. Published by Elsevier Editora Ltda. All rights reserved. 
anesthesia induction. Anesthesia was induced with intravenous propofol. ECGs for all patients were performed during the $1^{\text {st }}$ and $3^{\text {rd }}$ minutes of induction, 3 minutes after administration of muscle relaxant, and at 5 minutes and 10 minutes after intubation. Pwd and QT intervals were measured on all ECGs. QTC intervals were determined using the Bazett formula. Heart rate (HR) and mean arterial pressure (MAP) were recorded before and after induction of anesthesia, immediately after intubation, and 1, 3, 5, 7 and 10 minutes after intubation.

Results: Compared with control, HR significantly increased in Group C, Group L and Group F after intubation. However, in Group E, there was no significant difference in HR values between control and after intubation. Compared with control, MAP significantly increased in Group C and Group $L$ after the intubation. However, in Group $E$ and Group F, there was no significant difference in MAP values between control and after the intubation. Compared with control, Pwd significantly increased in Group C after intubation. In Group L, Group F and Group E, there was no significant difference in Pwd values between control and after the intubation. Compared with control, QTC duration significantly increased in Group C and L after the intubation. In Group F and Group E, there was no significant difference in QTc durations between control and after the intubation. Conclusion: We concluded that administration of esmolol before intubation prevents tachycardia and an increase in MAP, Pwd and QTc duration caused by laryngoscopy and tracheal intubation. ๑ 2013 Sociedade Brasileira de Anestesiologia. Published by Elsevier Editora Ltda. All rights reserved.

\section{Introduction}

Anesthetic agents may display proarrhythmic and antiarrhythmic activity by inducing electrical activity through various mechanisms ${ }^{1}$. Other than the anesthetic agents used, existing heart disease and other concomitant systemic diseases, laryngoscopy and tracheal intubation, surgical manipulation, procedures performed on the patient, and medication may also cause arrhythmia in the intraoperative period ${ }^{2}$. These effects can be determined on 12-lead electrocardiograms (ECGs) by measuring P-wave dispersion (Pwd) and QT and corrected QT (QTC) intervals ${ }^{1-6}$. Pwd is defined as the difference between the maximum and minimum $P$-wave duration in 12 leads of surface ECGs. Pwd is simple and non-invasive indicator of atrial arrhythmia such as atrial flutter or atrial fibrillation 1,3-6. Increased Pwd is accepted as a predictor of postoperative atrial fibrillation after coronary artery surgery ${ }^{7,8}$. QT and QTC intervals are electrocardiographic indicators of ventricular repolarization. Prolongation of the QTC interval is associated with an increased risk of ventricular arrhythmias such as torsade de pointes ${ }^{4-6}$.

Previous studies demonstrated that Pwd and QTc intervals might be extended in conditions such as diabetes mellitus 9,10 , hypertension ${ }^{11,12}$, malnutrition ${ }^{5}$, subarachnoid hemorrhage ${ }^{6}$, obesity ${ }^{13,14}$ and metabolic syndrome ${ }^{15}$. Also Pwd and QTC intervals extended after laryngoscopy and tracheal intubation ${ }^{1,2}$. For this reason, in patients with prolonged Pwd and QTC interval, choice of anesthetic and adjuvant drugs is important.

The effects of esmolol ${ }^{16}$, lidocaine ${ }^{17}$ and fentanyl 4,18 on QTC intervals during induction of anesthesia have been studied; however, little research has been done on their effects on Pwd duration during induction of anesthesia. In this study, we hypothesized that esmolol, lidocaine and fentanyl would affect Pwd. To test our hypothesis, we investigated the effect of esmolol, lidocaine and fentanyl on P-wave dispersion (Pwd), QT and corrected QT (QTC) durations and hemodynamic responses to endotracheal intubation during propofol induction.

\section{Methods}

This prospective randomized study was conducted in MayNovember 2009 at Zonguldak Karaelmas University's School of Medicine Research and Practice Hospital, Department of Anesthesiology and Reanimation after obtaining the approval of the Hospital Ethics Board (date 05.22.2008, number: 2008/07, President Dr. EY Sipahi) and patient consents.

\section{Patients}

After obtaining the approval from the hospital ethics committee, we enrolled 80 adult patients aged $18-60$ years, with American Society of Anesthesiologists (ASA) Physical Status (PS) I and II, who were scheduled for elective non-cardiac surgery. Written informed consent was obtained from all participants. Age; ASAPS; serum sodium, potassium, calcium, chlorine and magnesium levels; and body mass index (BMI) were recorded. Thirty minutes prior to anesthesia induction, all patients were premedicated with intramuscular $0.07 \mathrm{mg} / \mathrm{kg}$ midazolam (Dormicum; Roche, Basel, Switzerland). In the operating theatre, a 20-gauge cannula was used for intravenous access and 5-7 mL. kg $^{-1}$ Ringer's Lactate (Ringer Laktat; Polifarma, Istanbul, Turkey) infusion was started.

Baseline arterial blood pressure, peripheral oxygen saturation, and ECG records were obtained. All patients were subjected to standard 12-lead ECG using a Hewlett Packard PageWriter 300pi ECG device (Andover, MA, USA), and control ECGs were recorded at a paper speed of $50 \mathrm{~mm} . \mathrm{sec}^{-1}$ with an amplitude of $1 \mathrm{mV} / \mathrm{cm}$ prior to anesthesia induction. After ECGs were recorded, patients were randomly divided into four groups using a random samples table. 


\section{Exclusion criteria}

Exclusion criteria were: pregnancy, anorexia $\left(\mathrm{BMI}<18 \mathrm{~kg} \cdot \mathrm{m}^{-2}\right)$, obesity $\left(\mathrm{BMI}>30 \mathrm{~kg} \cdot \mathrm{m}^{-2}\right)$, chronic liver and kidney diseases, electrolyte disorders, diabetes mellitus, hypothyroidism or hyperthyroidism, alcohol addiction, coronary artery disease, Chagas disease, cardiomyopathy, arterial hypertension, atrial and/or ventricular hypertrophy on ECG, arrhythmia, cardiomegaly, valvular disease, cardiac insufficiency, and use of medication that led to extended QT intervals $1,5,6,15$.

\section{Anesthesia induction}

In the control group $(n=20)$, patients previously received $5 \mathrm{ml}$ saline bolus, followed by a continuous infusion of saline. Anesthesia was induced by intravenous $2.5 \mathrm{mg} \cdot \mathrm{kg}^{-1}$ propofol (Propofol 1\% Fresenius; Fresenius Kabi, Uppsala, Sweden) ${ }^{1}$.

In the lidocaine group ( $n=20)$, patients previously received a bolus dose of lidocaine $1.5 \mathrm{mg} \cdot \mathrm{kg}^{-1}$, followed by a continuous infusion at $1.5 \mathrm{mg} \cdot \mathrm{kg}^{-1} \cdot \mathrm{h}^{-1}$. Next, anesthesia was induced intravenously with $2.5 \mathrm{mg}^{\mathrm{kg}}{ }^{-1}$ propofol (Propofol 1\% Fresenius; Fresenius Kabi, Uppsala, Sweden) ${ }^{1,19}$.

In the fentanyl group $(n=20)$, patients previously received a bolus dose of fentanyl $2 \mu \mathrm{g} . \mathrm{kg}^{-1}$, followed by a continous infusion at $1 \mu \mathrm{g} \cdot \mathrm{kg}^{-1} \cdot \mathrm{h}^{-1}$. Next, anesthesia was induced intravenously with $2.5 \mathrm{mg}^{\mathrm{kg}} \mathrm{kg}^{-1}$ propofol (Propofol 1\% Fresenius; Fresenius Kabi, Uppsala, Sweden) ${ }^{1,20}$.

In the esmolol group $(n=20)$, patients previously received a bolus dose of esmolol $0.5 \mathrm{mg} \cdot \mathrm{kg}^{-1}$, followed by a continuous infusion at $100 \mu \mathrm{g} \cdot \mathrm{kg}^{-1} \cdot \mathrm{h}^{-1}$. Next, anesthesia was induced intravenously with $2.5 \mathrm{mg}^{\mathrm{kg}}{ }^{-1}$ propofol (Propofol 1\% Fresenius; Fresenius Kabi, Uppsala, Sweden). All of the groups have received $6 \mathrm{mg} \cdot \mathrm{kg}^{-1} \cdot \mathrm{h}^{-1}$ propofol infusion for anesthesia maintenance ${ }^{1,21}$.

All groups received $0.1 \mathrm{mg} . \mathrm{kg}^{-1}$ vecuronium for muscle relaxation at the $3^{\text {rd }}$ minute of induction ${ }^{1}$. Intubation was performed at 3 minutes after vecuronium administration. Throughout the entire study, a $60 / 40 \%$ oxygen/air mixture was used as carrier gas. Patients were ventilated with end-tidal $\mathrm{CO}_{2}$ at $35-40 \mathrm{~mm} \mathrm{Hg}$. We planned to administer intravenous $0.5 \mathrm{mg}$ atropine (Atropin, Biofarma, Istanbul, Turkey) to patients with heart rate $<50$ beats. min $^{-1}$, and 5 mg ephedrine (Efedrin, Osel, Istanbul, Turkey) to those with mean arterial blood pressure $<30 \%$ of the control level for a minimum of 1 minute ${ }^{1}$.

ECGs were recorded during the $1^{\text {st }}$ and $3^{\text {rd }}$ minutes during anesthesia induction and 3 minutes after administration of muscle relaxant. Intubation was performed with a tube of appropriate size, and further ECGs were recorded at 5 and 10 minutes, respectively. We recorded heart rate (HR), mean blood pressure, peripheral oxygen saturation $\left(\mathrm{SpO}_{2}\right)$, and end-tidal carbon dioxide $\left(\mathrm{ETCO}_{2}\right)$ during the $1^{\text {st }}$ and $3^{\text {rd }}$ minute during anesthesia induction, 3 minutes after administration of muscle relaxant, and 1, 2, 3, 4, 5 and 10 minutes after intubation. Surgery began after obtaining values at 10 minutes post-intubation ${ }^{1}$.

Electrocardiography Analysis: Standard 12 derivation ECG recordings obtained from patients participating in the study with a paper speed of $50 \mathrm{~mm} \cdot \mathrm{sec}^{-1}$ and a deflection of $1 \mathrm{~mm} \cdot \mathrm{mV}^{-1}$ were analyzed (Hewlett Packard $\AA$, Pagewriter 300pı). Heart rate was calculated using mean RR time ${ }^{1,5,6,15}$.
Analysis of $\mathrm{P}$-wave dispersion: The beginning of $\mathrm{P}$-wave was defined as positive deflection from the isoelectric line, and the end as the point when the positive deflection returned to the isoelectric line. We excluded from the study any derivations where the beginning and end of $\mathrm{P}$-waves were not obvious. Pwd was the difference between the longest and shortest P-wave durations ${ }^{1,5,6,15}$.

Analysis of QT, QTc duration: The QT interval was defined as between the beginning of QRS complex and the point where $T$ waves descend onto the TP isoelectric line. When a $U$ wave interrupted the $T$ wave before returning to baseline, the QT interval was measured to the nadir of the curve between the $T$ and $U$ waves ${ }^{1,5,6}$. The corrected $Q T$ interval (QTc) was calculated using the Bazett formula; QTc (ms)=QT measured JRR (where RR is the RR interval) ${ }^{1,5,6,15}$.

Subjects who had less than 9 derivations assessed on the ECG were excluded from the study. All ECG measurements were evaluated three times by two experts who were not aware of the group allocation ${ }^{1,5,6,15}$.

Sample size calculation: Our primary endpoint was the $P$ wave dispersion duration changes after intubation. Sample size estimation was based on the study performed by Acampa et al. ${ }^{22}$. In order to detect a $20 \%$ change in Pwd duration ( $34 \pm 6.1$ msec control values in Acampa's study ${ }^{22}$ ), with an a error of 0.05 and a power of $90 \%$, we calculated that sample size should be at least 17 patients per group. Estimating an approximate $20 \%$ dropout rate, we included 20 patients in each group. The sample size estimation was performed using Power Calculator (http: / / www.dssresearch. com/KnowledgeCenter/toolkitcalculators/samplesizecalculators.aspx).

Statistical analysis: Statistical analyses were performed by using the Statistical Package for the Social Sciences (SPSS) version 16.0 for Windows (SPSS Inc., Chicago, IL, USA). Descriptive statistics included arithmetic means \pm standard deviation (SD) for numerical data, and numbers and percentages for categorical data. The Kolmogorov-Smirnov test was used to examine compatibility between measured variables and normal distribution. Mann-Whitney $U$ test was used to compare the averages of data with continuous measures such as: serum sodium, potassium, calcium, chlorine and magnesium values; Pwd; QT and QTc durations; and HR, mean arterial pressure, $\mathrm{ETCO}_{2}$ and $\mathrm{SpO}_{2}$ values. The Wilcoxon Signed Ranks Test was used to compare intragroup repeated measures, and the $x^{2}$ test was used to compare data that denoted frequency, such as sex and ASA risk category. A $p$ value $<0.05$ after Bonferroni correction $(p<0.0083)$ was considered significant.

\section{Results}

Our subjects were allocated randomly into four groups. The groups were similar in terms of ASA risk category, age, sex, height, weight, and serum sodium, potassium, calcium, chlorine and magnesium levels ( $p>0.0083$ ) (Tables 1 and 2$)$.

\section{Heart rate changes}

There were no significant differences between the control HR values of the groups $(p>0.0083)$ (Figure 1$)$. Mean HR changes between Group C and Groups L, F did not have significant difference $(p>0.0083$ ) (Figure 1$)$. When Groups $E$ and $C$ 
Table 1 Demographic and anthropometric data.

\begin{tabular}{|c|c|c|c|c|}
\hline & $\begin{array}{l}\text { Group C } \\
(n=20)\end{array}$ & $\begin{array}{l}\text { Group L } \\
(n=20)\end{array}$ & $\begin{array}{l}\text { Group F } \\
(n=20)\end{array}$ & $\begin{array}{l}\text { Group } E \\
(n=20)\end{array}$ \\
\hline Age (year) & $33.75 \pm 10.65$ & $34.50 \pm 9.97$ & $35.25 \pm 6.31$ & $34.70 \pm 6.23$ \\
\hline Weight (kg) & $75.40 \pm 9.89$ & $74.50 \pm 9.54$ & $75.85 \pm 8.45$ & $73.90 \pm 10.34$ \\
\hline Height (cm) & $170.10 \pm 8.57$ & $169.55 \pm 8.00$ & $169.00 \pm 6.04$ & $170.90 \pm 7.62$ \\
\hline \multicolumn{5}{|l|}{ ASA (n, \%) } \\
\hline I & 17 (85\%) & 15 (75\%) & $16(80 \%)$ & $15(75 \%)$ \\
\hline II & $3(15 \%)$ & 5 (25\%) & $4(20 \%)$ & $5(25 \%)$ \\
\hline \multicolumn{5}{|l|}{ Gender (n, \%) } \\
\hline $\mathrm{F}$ & 9 (45\%) & 9 (45\%) & $8(40 \%)$ & 8 (40\%) \\
\hline$M$ & $11(55 \%)$ & $11(55 \%)$ & $12(60 \%)$ & $12(60 \%)$ \\
\hline
\end{tabular}

Table 2 Biochemical data of groups.

\begin{tabular}{|c|c|c|c|c|c|}
\hline & Normal values & $\begin{array}{c}\text { Group C } \\
(n=20)\end{array}$ & $\begin{array}{l}\text { Group L } \\
(n=20)\end{array}$ & $\begin{array}{l}\text { Group F } \\
(n=20)\end{array}$ & $\begin{array}{l}\text { Group E } \\
(n=20)\end{array}$ \\
\hline Sodium (mmol. $\left.\mathrm{L}^{-1}\right)$ & $136-145$ & $143.10 \pm 3.17$ & $142.95 \pm 2.39$ & $143.05 \pm 1.95$ & $144.50 \pm 1.79$ \\
\hline Potassium (mmol.L-1) & $3.5-5.5$ & $4.43 \pm 0.46$ & $4.37 \pm 0.42$ & $4.56 \pm 0.34$ & $4.45 \pm 0.32$ \\
\hline Chlorine (mmol.L $\mathrm{L}^{-1}$ ) & $98-110$ & $104.38 \pm 3.18$ & $105.30 \pm 3.14$ & $105.93 \pm 2.89$ & $106.03 \pm 2.69$ \\
\hline Calcium (mg.dL ${ }^{-1}$ ) & $8.4-10.2$ & $9.37 \pm 0.51$ & $9.23 \pm 0.46$ & $9.36 \pm 0.42$ & $9.52 \pm 0.43$ \\
\hline Magnesium (mg. $\left.\mathrm{dL}^{-1}\right)$ & $1.3-2.7$ & $2.14 \pm 0.19$ & $2.12 \pm 0.17$ & $2.06 \pm 0.07$ & $2.16 \pm 0.17$ \\
\hline
\end{tabular}

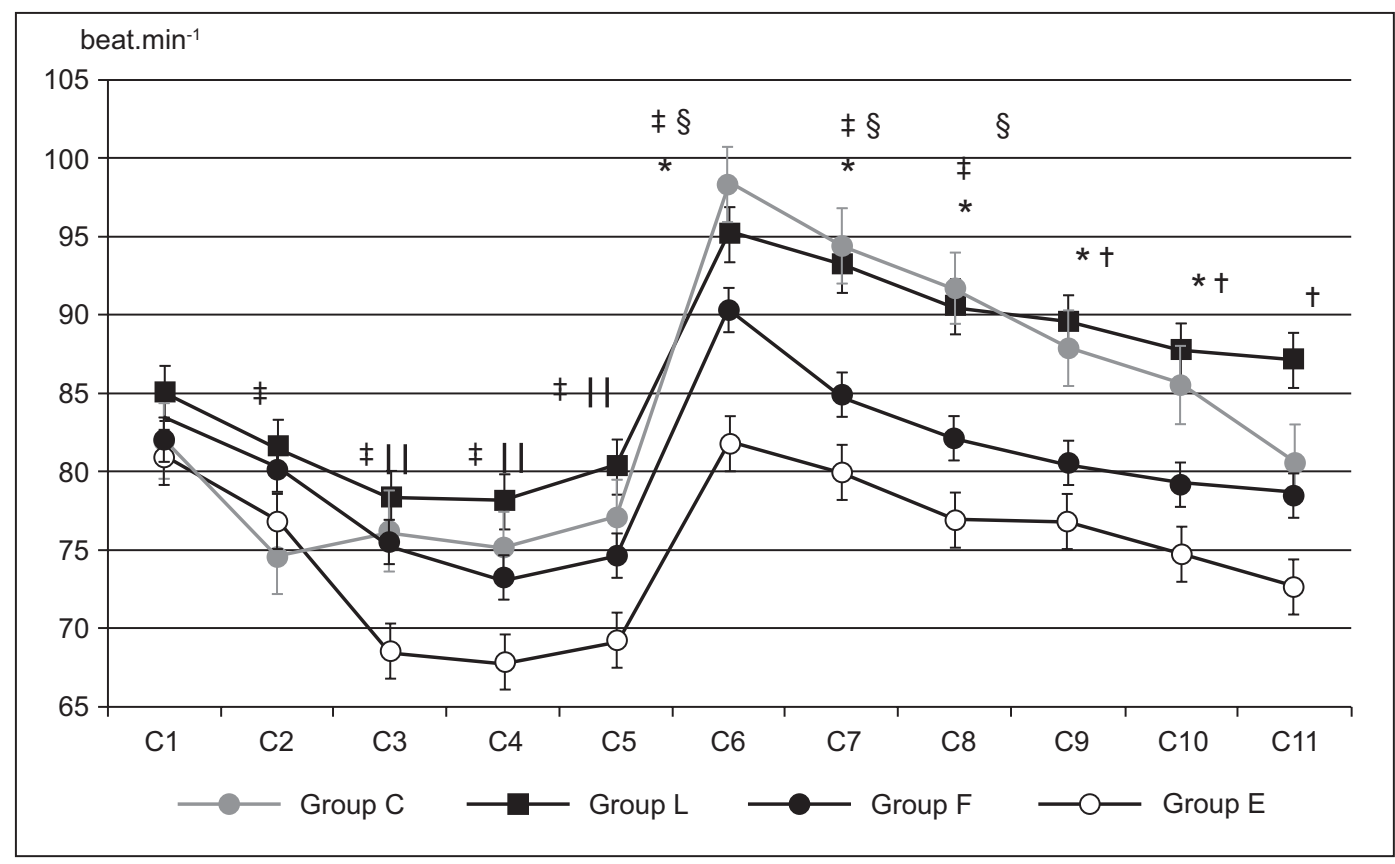

Figure 1 Changes in HR (beat. $\left.\mathrm{min}^{-1}\right)$.

P1 = Control, P2 = 1 minute after anesthesia induction; P3 = 3 minutes after anesthesia induction; P4 = 1 minute after administration of muscle relaxant; P5 = 3 minutes after administration of muscle relaxant; P6 = 1 minute after endotracheal intubation; P7 = 2 minutes after endotracheal intubation; P8 = 3 minutes after endotracheal intubation; P9 = 4 minutes after endotracheal intubation; P10 = 10 minutes after endotracheal intubation.

*: $\mathrm{p}<0.0083$ between Group C and Group E; $\dagger: \mathrm{p}<0.0083$ between Group L and Group E;

¥: $p<0.0083$ between control value in Group C; $\S: p<0.0083$ between control value in Group L;

I $:$ : $<0.0083$ between control value in Group F; $\uparrow: p<0.0083$ between control value in Group E. 
were compared in terms of HR values, Group E had lower HR values at 1, 2, 3 and 4 min after the intubation $(p<0.0083)$. In addition, Group E had lower HR values at 3, 4 and 5 min after intubation in comparison with group $L(p<0.0083)$ (Figure 1).

Intra-group analysis of Group $C$ has revealed that HR values, 1 and 3 min after the induction, 1, 2 and 3 min after the intubation were lower than the control HR value whereas 1,2 and 3 min after the intubation were higher than the control HR $(p<0.0083)$ (Figure 1).

HR values of Group L, at the $1^{\text {st }}$ and $2^{\text {nd }}$ min after intubation were higher than the control value $(p<0.0083)$. HR values of Group $F$, at the $3^{\text {rd }}$ min after the induction and $1^{\text {st }}$ and $3^{\text {rd }}$ after neuromuscular blockade were lower than the control value $(p<0.0083)$. HR values of Group E, at minute 3 after the induction, 1 and 3 min after neuromuscular blockade and 10 min after intubation were lower than the control value $(p<0.0083)$ (Figure 1).

\section{Mean blood pressure changes}

Basal mean arterial blood pressure values did not differ significantly among the groups ( $p>0.0083$ ). Groups $L$ and $\mathrm{F}$ did not have significant mean blood pressure changes in comparison with Group C ( $<<0.0083)$ (Figure 2).

Mean arterial blood pressure values at 2, 3 and $4 \mathrm{~min}$ after the intubation were lower in Group $\mathrm{E}$ in comparison with Group C ( $<$ 0.0083) (Figure 2).

When the groups were compared between themselves, mean MAP values at 1 and 3 min after induction and neuromuscular blockade, $10 \mathrm{~min}$ after the intubation were lower than control MAP values, whereas the MAP value at 1 min post-intubation was higher than the control value $(p<0.0083)$ (Figure 2).
In Group L, the control MAP value was significantly lower than the MAP values at 1 and $3 \mathrm{~min}$ after induction, $1 \mathrm{~min}$ after neuromuscular blockade administration, 5 and 10 min after the intubation ( $\mathrm{p}<0.0083$ ). In Group F, control MAP value was significantly lower than the MAP values at 1 and 3 min after induction and neuromuscular blockade administration, 4, 5 and 10 min after the intubation $(p<0.0083)$. In Group E, control MAP value was significantly lower than the MAP values at 1 and 3 min after induction and neuromuscular blockade administration, 3, 4, 5 and 10 min after the intubation $(p<0.0083)$ (Figure 2$)$.

\section{Changes in $\mathrm{SpO}_{2}$ vs. $\mathrm{ETCO}_{2}$}

Intragroup and intergroup statistical analysis revealed no significant difference in relation to $\mathrm{SpO}_{2}$ and $\mathrm{ETCO}_{2}$ $(p>0.0083)$.

\section{Electrocardiographic changes}

All patients included in the study had sinus rhythm. No patients had atrioventricular or bundlebranch block, atrial or ventricular premature beat, tachyarrhythmia or bradyarrhythmia. When ECG records were analyzed, no significant difference was observed in terms of PR interval variations between and within the groups $(p>0.0083)$.

\section{Changes in $P$ wave dispersion}

Control ECG records were similar in terms of Pwd duration ( $p>0.0083$ ) (Figure 3).

Pwd durations did not differ significantly between Group $\mathrm{L}, \mathrm{F}$ and Group $\mathrm{C}$ at any measurement time ( $\mathrm{p}>0.0083$ ). Measured Pwd values 5 and 10 min after the intubation in Group E were significantly lower than in Group C $(p<0.0083)$ (Figure 3).

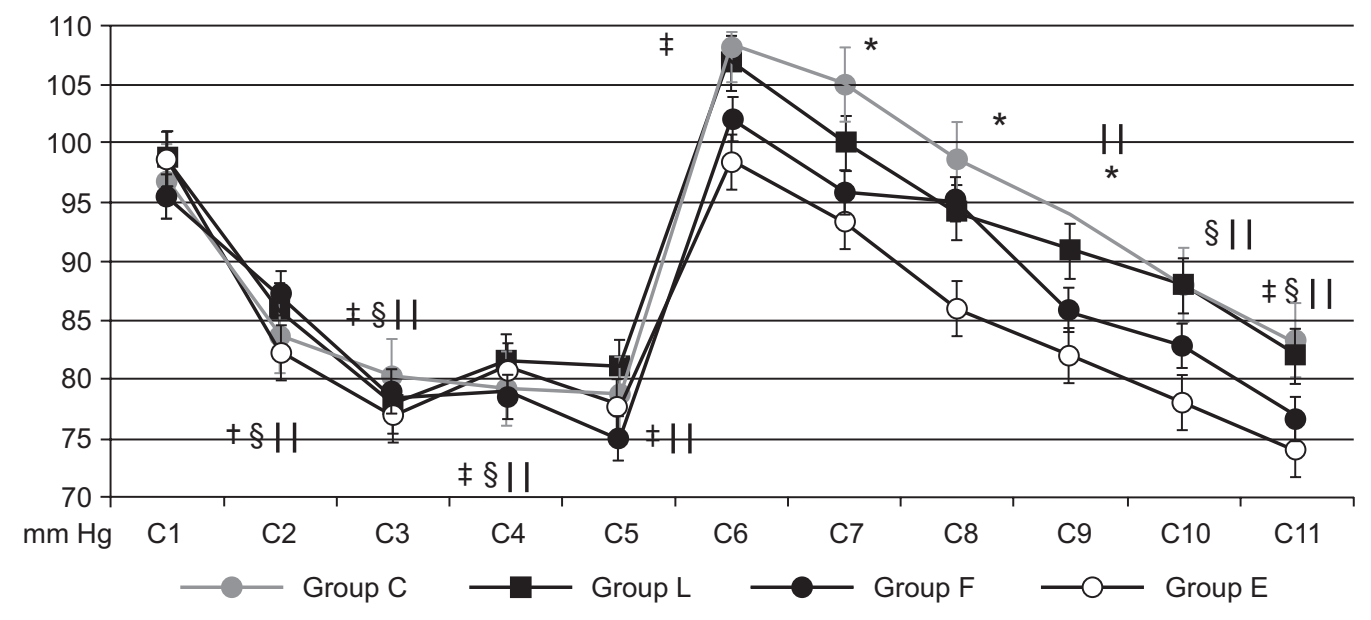

Figure 2 Changes in MAP $(\mathrm{mm} \mathrm{Hg})$.

P1 = Control, P2 = 1 minute after anesthesia induction; P3 = 3 minutes after anesthesia induction; P4 = 1 minute after administration of muscle relaxant; P5 = 3 minutes after administration of muscle relaxant; P6 = 1 minute after endotracheal intubation; P7 = 2 minutes after endotracheal intubation; P8 = 3 minutes after endotracheal intubation; P9 = 4 minutes after endotracheal intubation; P10 = 10 minutes after endotracheal intubation

*: $p<0.0083$ between Group C and Group E; $¥: p<0.0083$ between control value in Group C; s: $p<0.0083$ between control value in Group L; II: $p<0.0083$ between control value in Group F; ף: $p<0.0083$ between control value in Group E. 


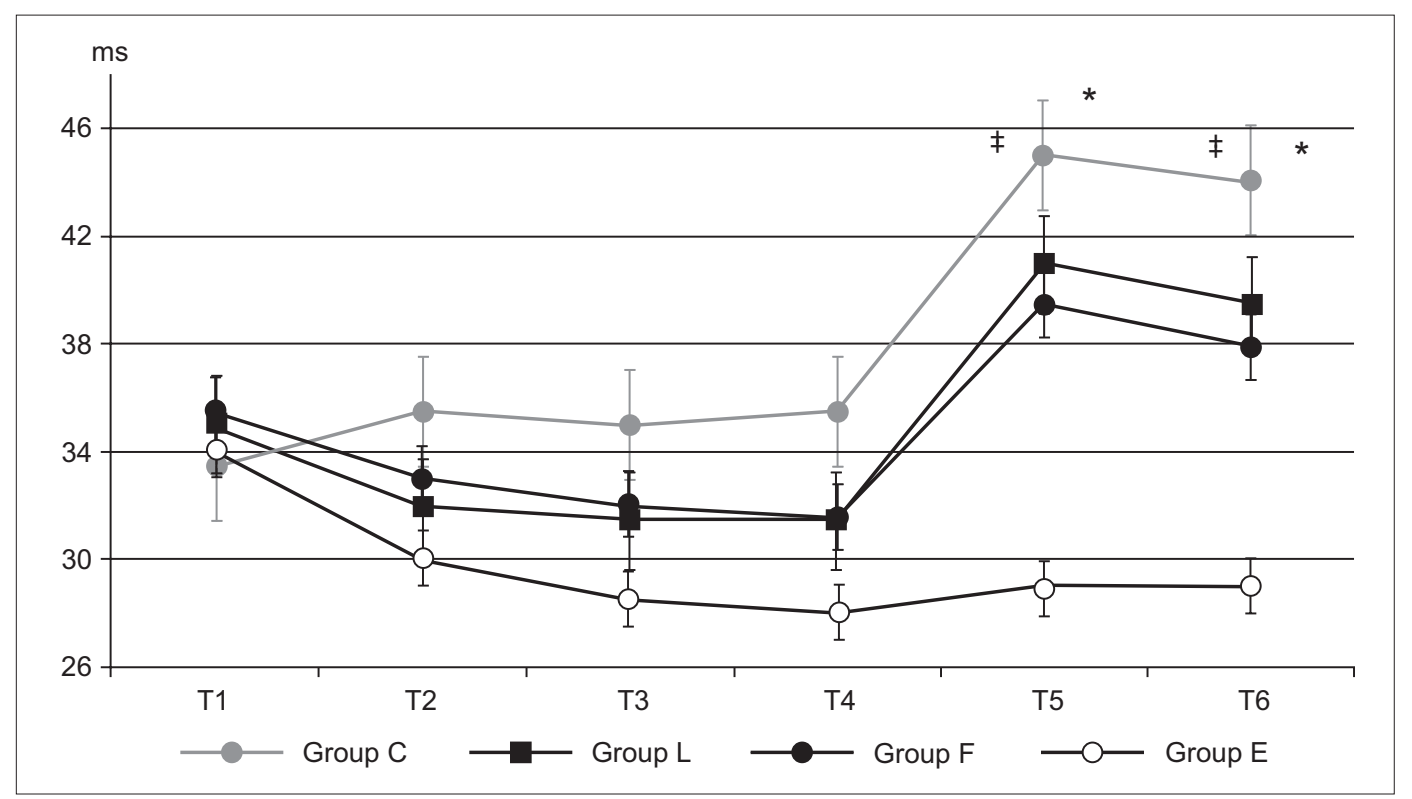

Figure 3 - Changes in Pwd (msec).

T1 = Control, T2 = 1 minute after anesthesia induction; T3 = 3 minutes after anesthesia induction; T4 = 3 minutes after administration of muscle relaxant; T5 = 5 minutes after endotracheal intubation; T6 = 10 minutes after endotracheal intubation.

*: $p<<0.0083$ between Group C and Group E; ¥: $p<0.0083$ between control value in Group C.

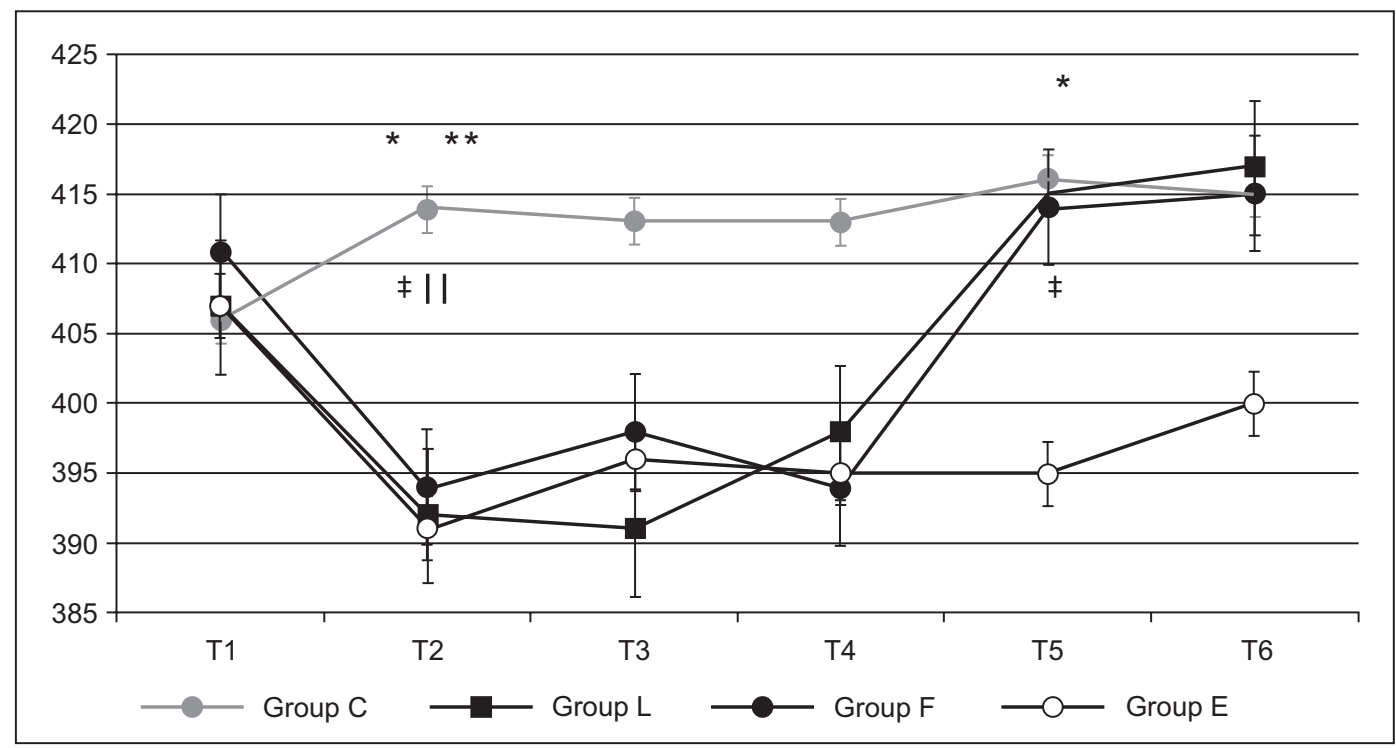

Figure 4 - Changes in QTc interval (msec).

T1 = Control, T2 = 1 minute after anesthesia induction; T3 = 3 minutes after anesthesia induction; T4 = 3 minutes after administration of muscle relaxant; T5 = 5 minutes after endotracheal intubation; T6 = 10 minutes after endotracheal intubation.

*: $p<0.0083$ between Group C and Group E; **: $p<0.0083$ between Group C and Group F; $\neq: p<0.0083$ between control value in Group C; II: $p<0.0083$ between control value in Group F. 
When the groups were compared within themselves, while there were no significant difference in Pwd durations between the Pwd durations of control and all measurement times ( $p>0.0083)$, Pwd durations at 5 and 10 minutes after the intubation were longer than control Pwd duration in Group C ( $<<0.0083)$ (Figure 3).

\section{Changes in QTC duration}

Groups were similar in terms of QTC duration at the control ECG records ( $p>0.0083$ ). Group $L$ and Group $C$ did not have significant difference in terms of QTc durations $(p>0.0083)$ (Figure 4).

QTc duration measured 1 min after the induction in Group $F$ was significantly shorter than in Group $C(p<0.0083)$. Measured QTC durations 1 min after the induction and 5 min after the intubation in Group E were significantly shorter than in Group C ( $<<0.0083$ ) (Figure 4).

When the Groups were compared within themselves, QTC durations $1 \mathrm{~min}$ after the induction and $5 \mathrm{~min}$ after the intubation were significantly longer than the control value in Group C ( $\mathrm{c}$ 0.0083). Measured QTc duration 1 min after the induction in Group $F$ was significantly shorter than the control QTC duration ( $<$ 0.0083) (Figure 4).

Although Group $L$ had shortening after the induction but prolongation in QTC durations after the intubation, QTC durations at all measurement times did not differ significantly compared with the control value. $(p>0.0083)$. In the same manner, QTC durations at all measurement times did not differ significantly either when compared with the control value in Group E. ( $p>0.0083)$.

\section{Discussion}

As a result of this prospective, randomised, double-blinded study on the effects of lidocaine, fentanyl and esmolol on the hemodynamic and electrocardiographic changes secondary to intubation, we have determined that esmolol had protective effects for tachycardia, increase of MAP and prolongation of Pwd, QTC durations.

Important increases can occur in arterial blood pressure, HR, and plasma catecholamine concentrations during laryngoscopy and endotracheal intubation ${ }^{23}$. Increase in hemodynamic parameters may lead to myocardial ischemia, infarction, arrythmia and cerebral hemorrhage in patients with coronary heart disease, hypertension or cerebrovascular disease ${ }^{24,25}$.

Prys-Roberts et al, has reported that reflex tachycardia and hypertension secondary to two different but consecutive stimuli manifest themselves during laryngoscopy, increase with intubation and are rapidly resolved when the endotracheal tube is placed and laryngoscope is withdrawn; nonetheless, concominant arrhtymias continue ${ }^{26}$.

Previous studies aiming to suppress hemodynamic responses accompanying laryngoscopy and tracheal intubation have defined utilization of glossopharyngeal and superior laryngeal nerve blocks, topical or systemic lidocaine, deep levels of anesthesia with intravenous or inhalational anesthesia, opioids ${ }^{27,28}$, magnesium sulphate, vasodilators ${ }^{29}$, calcium channel ${ }^{30}$, a or B adrenergic receptor blockers ${ }^{27,29,31}$.
On the other hand, studies comparing lidocaine, fentanyl and esmolol to suppress hemodynamic responses to intubation are limited.

In their study, Helfman et al. ${ }^{27}$ had given 200 mg lidocaine, $200 \mu \mathrm{g}$ or $150 \mathrm{mg}$ esmolol before anesthesia and induced it with $4-6 \mathrm{mg} . \mathrm{kg}^{-1}$ thiopenthal, $1-1.5 \mathrm{mg} . \mathrm{kg}^{-1}$ succinylcholine. They concluded that all three drugs were effective to block the increase in systolic blood pressure when compared to placebo. Additionally, researchers have reported that only the esmolol group had provided a stable and reliable protection against the increase in HR and systolic blood pressure.

Feng et al. ${ }^{32}$ have compared the hemodynamic effects of $2 \mathrm{mg} . \mathrm{kg}^{-1}$ lidocaine, $3 \mu \mathrm{g} . \mathrm{kg}^{-1}$ fentanyl or $2 \mathrm{mg} \cdot \mathrm{kg}^{-1}$ esmolol administration before anesthesia induction with $5 \mathrm{mg} \cdot \mathrm{kg}^{-1}$ thiopenthal and $1.5 \mathrm{mg} . \mathrm{kg}^{-1}$ succinylcholine. They have concluded that only esmolol has prevented the increase in both $\mathrm{HR}$ and blood pressure related to intubation. They reported that fentanyl was able to suppress increase in blood pressure but not the HR, whereas lidocaine was unable to suppress the response to laryngoscopy.

Ugur et al. ${ }^{33}$, in their similar study, compared $1.5 \mathrm{mg} \cdot \mathrm{kg}^{-1}$ esmolol, $1 \mu \mathrm{g} . \mathrm{kg}^{-1}$ fentanyl and $1.5 \mathrm{mg} \cdot \mathrm{kg}^{-1}$ lidocaine with respect to the hemodynamic responses to intubation. They concluded that esmolol administered 2 minutes before intubation was the most effective agent in preventing HR and rate-pressure product increase.

In the current study, we determined that esmolol was the most efficient agent to depress the reflex response to laryngoscopy and tracheal intubation, in parallel with previous studies $27,32,33$.

Prolonged QT interval may cause arrhythmias such as polymorphic ventricular tachycardia or ventricular fibrilation. As QT interval changes along with heart rate - extending with bradycardia and shortening with tachycardia - independently of other factors, we found corrected QT interval according to heart rate interval (QTC). Even though a QTc interval of 440 milliseconds is considered prolonged, serious arrhythmias generally occur with a QTC interval of 600 milliseconds or longer ${ }^{1,5,6,15,34}$. Prolonged QRS duration and increased dispersion of repolarization had been demonstrated to increase the risk of arrhythmic cardiac death in coronary artery disease patients ${ }^{1,5,35}$. Therefore, prevention of the increase in HR, MAP, Pwd and QTc durations are important priorities for the induction of anesthesia in patients with prolonged QT, QTc, Pwd durations.

Previous studies demonstrated that QTc interval might be extended in conditions such as diabetes mellitus 10 prehypertension ${ }^{12}$, subarachnoid hemorrhage ${ }^{6}$, malnutrition ${ }^{5}$, obesity ${ }^{14}$ and metabolic syndrome ${ }^{15}$. QTC intervals also extend after laryngoscopy and tracheal intubation ${ }^{1,2}$. Therefore, in patients with prolonged QTc interval, the choice of anesthetic and adjuvant drugs is important. Previously, it was demonstrated that inhalation anesthetic agents such as desflurane, sevoflurane, isoflurane, enflurane or halothane, extend the QTC interval duration ${ }^{1,3,4,17}$. Despite the fact that etomidate and midazolam have no effects on the ventricle repolarization ${ }^{3,17}$, they are not popular drugs for anesthesia induction. Propofol as an intravenous anesthetic agent is a popular choice for anesthesia induction in patients with prolonged QT, QTc, and Pwd interval, since it causes minimal prolongation of QT, QTc, and Pwd interval 1. In 
the present study, we used propofol as an induction agent and choose a muscle relaxant with minimal cardiovascular side effects ${ }^{1,16}$.

It is known that, laryngoscopy and tracheal intubation significantly increase the QTc duration ${ }^{1,4,16-18}$. Previous studies demonstrated that, esmolol ${ }^{16}$, lidocaine ${ }^{17}$ and fentanyl 4,18 attenuated QTC interval prolongation associated with tracheal intubation. However, studies regarding the comparative effect of lidocaine, fentanyl and esmolol on QTC duration during laryngoscopy and tracheal intubation are limited 4,16-18. Although QTc intervals after the intubation and laryngoscopy did not present a significant difference between lidocaine, fentanyl and esmolol groups in the present study, when the results were compared to the control group, the most effective agent to prevent QTc prolongation after the intubation was found to be esmolol.

It is known that lidocaine's effect on cardiomyocytes is inadequate to prevent heart repolarization ${ }^{36}$. Due to its anti-arrhythmic characteristics, lidocaine is used in the treatment of heart rate disturbances of ventricular origin ${ }^{37}$. In an earlier study researching the effect of lidocaine on QTC interval prolongation associated with tracheal intubation ${ }^{17}$, researchers speculated that this effect of lidocaine could be associated with protective activation of the sympathetic system secondary to airway manipulation and, thus, inhibition of the prolonged repolarization ${ }^{17}$. However, literature on this matter is confounding. Other studies demonstrated that lidocaine administration before intubation was unable to suppress the laryngoscopy and intubation-related sympathetic activity ${ }^{27,32,33,38}$. In addition, significant MAP increases were observed in lidocaine groups after intubation in Owczuk et al.'s ${ }^{17}$ study, which raises the possibility of insufficient lidocaine efficacy in inhibiting sympathetic activation.

The previous studies on fentanyl for QTc interval are controversial ${ }^{39,40}$. Wilton et al. ${ }^{39}$ reported that fentanyl is associated with a decrease in the QTc interval in a patient with long QT syndrome. However another study on this topic demonstrated QTc interval prolongation after fentanyl injection in patients undergoing coronary artery bypass graft operation ${ }^{40}$.

It is known that beta-blockers, such as metoprolol, atenolol, reduce the cardiovascular response to sympathetic stimulation and therefore, could prevent arrhythmias. Beta-blockers' anti-sympathetic and anti-ischemic effect can cause QTC duration decrease ${ }^{16}$. Erdil et al ${ }^{16}$ and Korpinen et al. ${ }^{41}$ reported that esmolol shortens the QTC interval after the laryngoscopy and intubation. However, other studies ${ }^{42-45}$ reported that esmolol prevented the prolongation of the QTC interval following the administration of intravenous anesthetic agents, but not following laryngoscopy and intubation.

On the other hand, the administration of esmolol may produce a clinically significant reduction in HR and MAP 46,47. These effects may cause hemodynamic depression, which may lead to increased myocardial ischemia in susceptible patients, especially in combination with anesthesia induction agents ${ }^{41}$. However, we did not observe any hemodynamic hazard associated with esmolol.

We believe the differences among the studies can be attributed to patients' gender distribution, premedication status, and the use of different induction and adjuvant drugs in the anesthesia induction and maintenance periods.
Anesthetic substances may affect $P$ wave dispersion (Pwd). The general anesthetic sevoflurane has been reported to prolong Pwd, while desflurane has no effect on it, and propofol shortens it 1,48,49. Pwd intervals also extend after laryngoscopy and tracheal intubation ${ }^{1}$. However, to the best of our knowledge, there is no data about evaluating the effect of lidocaine, fentanyl and esmolol on prolonged Pwd due to laryngoscopy and tracheal intubation.

We have determined that Pwd was prolonged in the control group following laryngoscopy and tracheal intubation. Although Pwd durations were prolonged after the intubation in lidocaine and fentanyl groups, when compared to control value Pwd durations did not increase significantly in either group. In contrary, Pwd durations after intubation were significantly different between the control and esmolol groups. Therefore, only esmolol suppresses the prolongation in Pwd duration after intubation. Studies have demonstrated that $B$ blocker agents like nebivolol ${ }^{50,51}$, atenolol ${ }^{51,52}$ and metoprolol ${ }^{53}$ returned Pwd duration to normal values in the event that it is prolonged due to various reasons. However, most of these agents are not available in intravenous form in order to use at anesthesia induction, second, esmolol has the shortest elimination half-life among them making it a very suitable agent for procedures with a brief duration.

One of the limitations of our study is the manual calculation of Pwd on paper ECG. Also, we only searched Pwd, QT, and QTc changes at induction of anesthesia. Therefore, it might be better if future studies include the whole perioperative process with Holter monitoring, which would probably document any increased rate of atrial and ventricular arrhythmias due to its higher quality ${ }^{1}$.

We conclude that administration of esmolol before intubation prevents tachycardia and an increase in MAP, Pwd and QTC durations caused by laryngoscopy and tracheal intubation. Esmolol should be used for anesthesia induction in patients with a predisposition to preoperative arrhythmias, and in those whose Pwd and QTc durations are prolonged on their preoperative ECGs.

\section{References}

1. Hanci V, Aydin M, Yurtlu BS, et al. - Anesthesia induction with sevoflurane and propofol: evaluation of P-wave dispersion, QT and corrected QT intervals. Kaohsiung J Med Sci. 2010;26:470477.

2. Ugur B, Yüksel H, Odabasi AR, Ogurlu M, Onbasili A, Aydin ON Effects of intravenous lidocaine on QTd and HRV changes due to tracheal intubation during sevoflurane induction. Int Heart J. 2006;47:597-606.

3. Owczuk R, Wujtewicz MA, Sawicka W, et al. - Effect of anaesthetic agents on $\mathrm{p}$-wave dispersion on the electrocardiogram: comparison of propofol and desflurane. Clin Exp Pharmacol Physiol. 2008;35:1071-1076.

4. Chang DJ, Kweon TD, Nam SB, et al. - Effects of fentanyl pretreatment on the QTC interval during propofol induction. Anaesthesia. 2008;63:1056-1060.

5. Hancl V, Ayoğlu H, Yurtlu S, et al. - An evaluation of $P$ wave dispersion, QT, QTC and QTc dispersion intervals on the electrocardiograms of malnourished adults. Anaesth Inten Care. 2010;38:122-127.

6. Hancı V, Gül S, Dogan SM, et al. - Evaluation of P wave and QTc dispersion in subarachnoid hemorrhage. Anaesth Inten Care. 2010;38:128-132. 
7. Chandy J, Nakai T, Lee RJ, et al. - Increases in P wave dispersion predict postoperative atrial fibrillation after coronary artery bypass graft surgery. Anesth Analg. 2004;98:303-310.

8. Dagdelen $\mathrm{S}$, Toraman $\mathrm{F}$, Karabulut $\mathrm{H}$, et al. - The value of $\mathrm{P}$ dispersion on predicting atrial fibrillation after coronary artery bypass surgery: effect of magnesium on $\mathrm{P}$ dispersion. Ann Noninvasive Electrocardiol. 2002;7:211-218.

9. Yazici M, Ozdemir K, Altunkeser BB, et al. - The effect of diabetes mellitus on the P-Wave dispersion. Circ J. 2007; 71:880883.

10. Stettler C, Bearth A, Allemann S, et al. - QTC interval and resting heart rate as long-term predictors of mortality in type 1 and type 2 diabetes mellitus: a 23-year follow-up Diabetologia. 2007;50:186-194.

11. Cagirci G, Cay S, Karakurt O, et al. - P-Wave dispersion increases in prehypertension. Blood Press. 2009;18:51-54.

12. Dogru MT, Güneri M, Tireli E, et al. - QT interval and dispersion differences between normal and prehypertensive patients: effects of autonomic and left ventricular functional and structural changes. Anadolu Kardiyol Derg. 2009;9:15-22.

13. Kosar F, Aksoy Y, Ari F, et al. - P-wave duration and dispersion in obese subjects. Ann Noninvasive Electrocardiol. 2008;13:3-7.

14. Bezante GP, Scopinaro A, Papadia F, et al. - Biliopancreatic diversion reduces QT interval and dispersion in severely obese patients. Obesity. 2007;15:1448-54.

15. Hanci V, Yurtlu S, Aydin M, et al. - Preoperative abnormal P and QTC dispersion intervals in patients with metabolic syndrome. Anesth Analg. 2011;112:824-827.

16. Erdil F, Demirbilek S, Begec Z, Ozturk E, But A, Ozcan Ersoy $M$. The effect of esmolol on the QTc interval during induction of anaesthesia in patients with coronary artery disease. Anaesthesia. 2009;64:246-250.

17. Owczuk R, Wujtewicz MA, Sawicka W, et al. - The effect of intravenous lidocaine on QT changes during tracheal intubation. Anaesthesia. 2008;63:924-931.

18. Cafiero T, Di Minno RM, Di lorio C - QT interval and QT dispersion during the induction of anesthesia and tracheal intubation: a comparison of remifentanil and fentanyl. Minerva Anestesiol. 2011;77:160-165.

19. Baral BK, Bhattarai BK, Rahman TR, Singh SN, Regmi R Perioperative intravenous lidocaine infusion on postoperative pain relief in patients undergoing upper abdominal surgery. Nepal Med Coll J. 2010;12:215-220.

20. Inomata S, Maeda T, Shimizu T, Satsumae T, Tanaka M - Effects of fentanyl infusion on tracheal intubation and emergence agitation in preschool children anaesthetized with sevoflurane. Br J Anaesth. 2010;105:361-367.

21. Amr YM, Amin SM - Effects of preoperative oral beta blocker versus intraoperative nitroprusside or esmolol on quality of surgical field during tympanoplasty. J Clin Anesth. 2011;23:544548.

22. Acampa M, Lazzerini PE, Guideri F, et al. - Homocysteine and $P$ wave dispersion in patients with heart transplantation. Clin Transplant. 2011;25:119-125.

23. Derbyshire DR, Chmielewski A, Fell D, Vater M, Achola K, Smith $\mathrm{G}$ - Plasma catecholamine responses to tracheal intubation. $\mathrm{Br}$ J Anaesth. 1983;55:855-860.

24. Thomson IR - The hemodynamic response to intubation: a perspective. Can J Anaesth. 1989; 36:367-369.

25. Kovac AL - Controlling the hemodynamic response to laryngoscopy and endotracheal intubation. J Clin Anesth. 1996; 8:63-79.

26. Prys-roberts C, Greene LT, Meloche R - Studies of anaesthesia in relation to hypertansion II: haemodynamic consequences of induction and endotracheal intubation. $\mathrm{Br} \mathrm{J}$ Anaesth. $1971 ; 43: 531-546$
27. Helfman MS, Gold IM, DeLisser AE - Which drug prevents tachycardia and hypertension associated with tracheal intubation: lidocaine, fentanyl or esmolol. Anesth Analg. 1991;72:482-486.

28. Guignard B, Menigaux C, Dupont X, et al. - The effect of remifentanil on the bispectral index change and hemodynamic responses after orotracheal intubation. Anesth Analg. 2000;90:161-167.

29. Van den Berg AA, Sava D, Honjol NM - Attenuation of hemodynamic responses to noxious stimuli in patients undergoing cataract surgery. A comparison of magnesium sulphate, esmolol, lidocaine, nitroglycerine and placebo given i.v. with induction of anaesthesia. Eur J Anaesthesiol. 1997;14:134-147.

30. Tan PH. Yang LC, Shih HC - Combined use of esmolol and nicardipine to blunt the hemodynamic changes following laryngoscopy and tracheal intubation. Anaesthesia. 2002;57:1195-212.

31. Muzzi DA, Susan B, Losasso JT - Labetalol and Esmolol in the control of hypertension after intracranial surgery. Anesth Analg. 1990;70:68-71.

32. Feng $\mathrm{CK}$, Chan $\mathrm{KH}$, Liu KN, Or CH, Lee TY - A comparison of lidocaine, fentanyl, and esmolol for attenuation of cardiovascular response to laryngoscopy and tracheal intubation. Acta Anaesthesiol Sin. 1996;34:61-67.

33. Ugur B, Ogurlu M, Gezer E, Nuri Aydin O, Gürsoy F - Effects of esmolol, lidocaine and fentanyl on haemodynamic responses to endotracheal intubation: a comparative study. Clin Drug Investig. 2007;27:269-277.

34. Owczuk R, Sawicka W, Wujtewicz MA, Kawecka A, Lasek J, Wujtewicz M - Influence of spinal anesthesia on corrected QT interval. Reg Anesth Pain Med. 2005;30:548-552.

35. Zareba W, Moss AJ, le Cessie S - Dispersion of ventricular repolarization and arrhythmic cardiac death in coronary artery disease. Am J Cardiol. 1994;74:550-553.

36. Newman D - Overview of lidocaine. Cardiac Electrophysiology Review. 2000;4:248-250.

37. Khan IA, Gowda RM - Novel therapeutics for treatment of long-QT syndrome and torsade de pointes. Int J Cardiol. 2004;95:1-6.

38. Lin PL, Wang YP, Chou YM, Chan HL, Huang HH - Lack of intravenous lidocaine effects on HRV changes of tracheal intubation during induction of general anesthesia. Acta Anaesthesiologica Sinica. 2001;39:77-82.

39. Wilton NC, Hantler CB - Congenital long QT syndrome: changes in QT interval during anesthesia with thiopental, vecuronium, fentanyl, and isoflurane. Anesth Analgesia. 1987;66:357-360.

40. Lischke V, Wilke HJ, Probst S, Behne M, Kessler P - Prolongation of the QT-interval during induction of anesthesia in patients with coronary artery disease. Acta Anaesthesiol Scand. 1994;38:144148.

41. Korpinen R, Simola M, Saanivaara L - Effect of esmolol on the hemodynamic and electrocardiographic changes during laryngomicroscopy under propofol-alfentanil anesthesia. Acta Anaesthesiol Belg. 1998;49:123-132.

42. Korpinen R, Saanivaara L, Siren K - QT interval of the ECG, heart rate and arterial pressure during anaesthetic induction: comparative effects of alfentanil and esmolol. Acta Anaesthesiol Scand. 1995;39:809-813.

43. Korpinen R, Saarnivaara L, Siren K, Sarna S - Modification of the haemodynamic responses to induction of anaesthesia and tracheal intubation with alfentanil, esmolol and their combination. Can J Anaesthesia. 1995;42:298-304.

44. Korpinen R, Simola M, Saarnivaara L - Effect of esmolol on the heart rate, arterial pressure and electrocardiographic changes during laryngomicroscopy. Acta Anaesthesiol Scand. 1997;41:371-375. 
45. Korpinen R, Klemola UM, Simola M, Toivonen H - The electrocardiographic and hemodynamic effect of metohexital and propofol with and without esmolol. Acta Anaesthesiol Scand. 2006;50:188-192.

46. Alexander R, Binns J, Hetreed M - A controlled trial of the effects of esmolol on cardiac function. Br J Anaesthesia. 1994;72:594595.

47. Sharma S, Mitra S, Grover VK, Kalra R - Esmolol blunts the haemodynamic responses to tracheal intubation in treated hypertensive patients. Can J Anaesthesia. 1996;43:778-782.

48. Kazanci D, Unver S, Karadeniz U, et al. - A comparison of the effects of desflurane, sevoflurane and propofol on QT, QTc, and P dispersion on ECG. Ann Card Anaesth. 2009;12:107-112.

49. Owczuk R, Wujtewicz MA, Sawicka W, et al. - Effect of anaesthetic agents on $\mathrm{p}$-wave dispersion on the electrocardiogram: comparison of propofol and desflurane. Clin Exp Pharmacol Physiol. 2008;35:1071-1076.
50. Güneș Y, Tuncer M, Güntekin U, Ceylan $Y$ - The effects of nebivolol on $\mathrm{P}$ wave duration and dispersion in patients with coronary slow flow. Anadolu Kardiyol Derg. 2009;9:290-295.

51. Tuncer M, Fettser DV, Gunes Y, et al. - Comparison of effects of nebivolol and atenolol on P-wave dispersion in patients with hypertension. Kardiologiia. 2008;48:42-45.

52. Tuncer M, Gunes Y, Guntekin U, Gumrukcuoglu HA, Eryonucu $B$ - Short-term effects of cilazapril and atenolol on P-wave dispersion in patients with hypertension. Adv Ther. 2008;25:99105.

53. Turgut O, Yilmaz MB, Yilmaz A, Yalta K, Kendirlioglu O, Tandogan I - Acute coronary syndrome: short-term effects of early intravenous metoprolol on maximum $\mathrm{P}$ wave duration and $\mathrm{P}$ wave dispersion. Adv Ther. 2007;24:14-22. 